\title{
Triagem de casos suspeitos ou confirmados de SARS-CoV-2 por residentes de enfermagem
}

\author{
Screening of suspected or confirmed cases of SARS-CoV-2 by nursing residents \\ Detección de casos sospechosos o confirmados de SARS-CoV-2 por parte de \\ residentes de enfermería
}

\begin{abstract}
Maria Julia Navarro Kassim ${ }^{1 *}$, Gabriele da Silva Borges ${ }^{1}$, Fabiana Gonçalves de Oliveira Azevedo Matos $^{1}$, Maristela Salete Maraschin ${ }^{1}$, Josni Tauffer ${ }^{2}$, Marcielle Cândido'1.
\end{abstract}

\section{RESUMO}

Objetivo: Relatar a experiência dos residentes de enfermagem na triagem de pacientes suspeitos ou confirmados de infecção por SARS-CoV-2 em um Hospital Universitário do sul do Brasil. Relato de experiência: Do tipo descritivo-reflexivo, baseado na atuação de residentes de enfermagem na triagem em um hospital escola paranaense entre os anos de 2020 e 2021. Os residentes cumpriam escalas de trabalho de 06 horas diárias e eram responsáveis por determinar o fluxo dos atendimentos. O serviço de triagem dos pacientes foi planejado e estruturado de acordo com as orientações sanitárias nacionais e internacionais vigentes, e a finalidade de evitar a disseminação da COVID-19 por meio da adoção das medidas preventivas. O local destinado à triagem era localizado em uma área estratégica, permitindo o correto fluxo de pacientes e acompanhantes para os diferentes setores do referido serviço de saúde. Considerações finais: Em meio a uma crise mundial provocada por um vírus respiratório com alta proliferação e letalidade, acreditamos que a implementação do serviço de triagem tenha contribuído para aumentar a segurança de todos os trabalhadores que atuam na instituição. A experiência relatada acarretou acréscimos importantes para a formação dos enfermeiros residentes, proporcionando vivências únicas, pessoais e profissionais.

Palavras-chave: Triagem, Infecções por Coronavirus, Enfermagem.

\begin{abstract}
Objective: To report the experience of nursing residents in screening patients suspected or confirmed for SARS-CoV-2 infection at a University Hospital in southern Brazil. Experience report: Descriptive-reflective type, based on the performance of nursing residents in screening at a teaching hospital in Paraná between the years 2020 and 2021. The residents fulfilled work schedules of 06 hours a day and were responsible for determining the flow of calls. The screening service for patients was planned and structured in accordance with current national and international health guidelines, and the purpose of preventing the dissemination of COVID-19 through the adoption of preventive measures. The location for the triage was located in a strategic area, allowing the correct flow of patients and caregivers to the different sectors of the aforementioned health service. Final considerations: In the midst of a global crisis caused by a respiratory virus with high proliferation and lethality, we believe that the implementation of the screening service has contributed to increasing the safety of all workers working in the institution. The experience reported brought important additions to the training of resident nurses, providing unique, personal and professional experiences.
\end{abstract}

Keywords: Screening, Coronavirus infections, Nursing.

1 Universidade Estadual do Oeste do Paraná (UNIOESTE), Cascavel - PR.

*E-mail: mjkassim_enfermagem@hotmail.com

2 Universidade Fe⿳亠口冋lal de São Paulo (UNIFESP), São Paulo - SP.

SUBMETIDO EM: 6/2021 | ACEITO EM: 6/2021 | PUBLICADO EM: 6/2021 


\section{RESUMEN}

Objetivo: Informar la experiencia de los residentes de enfermería en el cribado de pacientes con sospecha o confirmación de infección por SARS-CoV-2 en un Hospital Universitario del sur de Brasil. Informe de experiencia: Tipo descriptivo-reflexivo, basado en el rol de los residentes de enfermería en el triaje en un hospital universitario de Paraná entre 2020 y 2021. Los residentes completaron horarios de trabajo de 06 horas diarias y fueron los encargados de determinar el flujo dos atenciones. El servicio de cribado a los pacientes fue planificado y estructurado de acuerdo con las directrices sanitarias nacionales e internacionales vigentes, y el propósito de prevenir la diseminación del COVID-19 mediante la adopción de medidas preventivas. La ubicación para el triaje se ubicó en una zona estratégica, permitiendo el correcto flujo de pacientes y cuidadores a los diferentes sectores del mencionado servicio de salud. En medio de una crisis global provocada por un virus respiratorio con alta proliferación y letalidad, creemos que la implementación del servicio de cribado ha contribuido a incrementar la seguridad de todos los trabajadores que laboran en la institución. Consideraciones finales: La experiencia relatada aportó importantes aportes a la formación de los enfermeros residentes, aportando experiencias únicas, personales y profesionales.

Palabras clave: Detección, Infecciones por Coronavirus, Enfermería.

\section{INTRODUÇÃO}

Atualmente, existem sete tipos de coronavírus reconhecidos por infectarem e causarem doenças respiratórias em humanos. De certa forma, esses vírus são sazonais e causadores das síndromes gripais, uma delas conhecida por síndrome respiratória aguda grave (SRAG) (OLIVEIRA WA, 2020). Em dezembro de 2019, na cidade chinesa de Wuhan, foram diagnosticados vários casos de pneumonia de origem desconhecida (BRANCO A, et al., 2020; OLIVEIRA WA, 2020). Após investigação e análise, foi identificado um microrganismo que descendia da família de betacoronavírus, sendo identificado como novo coronavírus, denominado SARS-CoV-2 (Severe Acute Respiratory Syndrome Coronavirus 2) (BRANCO A, et al., 2020; MACHADO R, et al., 2020).

A doença se disseminou para os demais continentes e no final de janeiro de 2020 , foi declarado estado de emergência de saúde pública global (MACHADO R, et al., 2020). Até o dia 27 de fevereiro de 2021, o coeficiente de incidência de COVID-19 a nível mundial era de 14.597,5 casos para cada 1 milhão de habitantes e no Brasil esse coeficiente era de 49.666,8 casos para cada 1 milhão de habitantes (BRASIL, 2021).

A disseminação do SARS-CoV-2 é rápida e ocorre por meio de gotículas e aerossóis de pessoas contaminadas (DOREMALEN NV, et al., 2020). Estima-se que para cada pessoa infectada outras quatros pessoas são contaminadas (LIMA CKT, et al., 2020). A evolução da infecção é rápida, sendo necessário diagnóstico precoce para instituir medidas de isolamento efetivas a fim de diminuir o aumento de casos deste agravo (ESTEVÃO A, 2020). Em frente a indisponibilidade das vacinas de forma ampliada e de medicamentos específicos para o tratamento da referida doença, as medidas de precaução mais eficazes são: higienização das mãos, distanciamento social e precaução respiratória (GARCIA LP, 2020).

Entre os sinais clínicos da doença ocasionada pelo SARS-CoV-2 pode-se destacar: dor de garganta, cefaleia, calafrios, tosse, febre $\geq 37,8^{\circ} \mathrm{C}$, dispneia, mialgias, fadiga ou cansaço, diarreia, anosmia e ageusia (ANTUNES CMTB, et al., 2020). Os referidos sintomas, mesmo que inespecíficos, devem ser avaliados por meio da triagem, cuja função é identificar os indivíduos com suspeita da doença, no entanto, os pacientes assintomáticos, por não apresentar sinais da doença, podem corroborar com a propagação do virus (KAWAKAMI RMSA, et al., 2020). Profissionais da saúde, pessoas com mais de 65 anos, portadores de hipertensão arterial sistêmica (HAS), diabetes mellitus (DM), doenças imunossupressoras, doenças neoplásicas, doença pulmonar obstrutiva crônica (DPOC), doença renal crônica e hepatopatas fazem parte do grupo de risco para tal doença (GUIMARÃES ASM, et al., 2020). 
O método diagnóstico padrão outro da infecção por SARS-CoV-2 se dá por meio da técnica de testagem molecular RT-PCR (Reverse-Transcriptase Polymerase Chain Reaction) que objetiva a amplificação dos ácidos nucleicos virais em tempo real, tendo como apoio diagnóstico as imagens tomográficas computadorizadas e a presença de sinais e sintomas (VIEIRA LMF, et al., 2020).

A coleta do material RT-PCR por swab nasofaríngeo deve ser realizada de preferência entre o terceiro e o sétimo dia após o início dos sintomas, sendo necessário identificar a amostra com o nome do paciente edata da coleta e acondicioná-lo em caixa térmica específica para essa finalidade, contendo placa de gelo para manter a temperatura entre 2 a 8드. (SILVEIRA JLO, et al., 2021).

O serviço de triagem para detecção de pacientes com COVID-19 foi instituído para todos os indivíduos regulados para os serviços de referência como hospitais com perfil de atendimento geral, pois o ambiente hospitalar constitui um fator de grande importância para atendimento desses casos e ao mesmo tempo, para o controle de doenças infectocontagiosas (BRASIL D, et al., 2021; OSHA, 2021; TEMIME L, et al, 2021).Cabe ao enfermeiro realizar a triagem de pacientes suspeitos ou confirmados de infecção por SARSCoV-2, pois o mesmo tem conhecimento técnico e científico para realizar a avaliação inicial do paciente eestabelecero fluxo correto de atendimentos (GUIMARÃES ASM, et al., 2020)

O Ministério da Saúde (MS) estabeleceu a ação estratégica chamada de "O Brasil Conta Comigo Residentes na área de Saúde", cuja finalidade é mobilizá-los para o enfrentamento à pandemia, promovendo a ampliação da força de trabalho no SUS com o intuito de proporcionar uma melhor assistência à população (CAETANO R, et al., 2021). Os programas de Residência em Saúde resultaram da força conjunta entre o Ministério da Saúde (MS) eo Ministério da Educação (ME) com o objetivo de promover ensino de qualidade aos profissionais da saúde (SILVA GF, et al., 2020).

O enfermeiro residente representa uma importante força de trabalho frente à atenção à saúde, e a partir dessa experiência, adquiremconhecimento nas diversas áreas de atuação, e ao mesmo tempo prestam serviço para a população (LOURENÇÃO LG, 2018).

Diante do exposto, frente ao contexto pandêmico vivenciado, o objetivo do estudo foi relatar a experiência dos residentes de enfermagem na triagem de pacientes suspeitos ou confirmados de infecção por SARS-CoV-2 em um Hospital Universitário do Sul do Brasil.

\section{RELATO DE EXPERIÊNCIA}

O presente estudo teve aprovação do Comitê de Ética em Pesquisa, com parecer número 4.047.913 e CAAE 90600318.3.0000.0107. Trata-se de estudo descritivo-reflexivo, do tipo relato de experiência, que permitiu explanar sobre as atividades realizadas pelos residentes de enfermagem durante a triagem de pacientes suspeitos ou confirmados de infecção por SARS-CoV-2 em um hospital escola paranaense.

O relato sumariza a experiência vivenciada por enfermeiros residentes vinculados ao Programa de Residência Multiprofissional em Reabilitação Integral das Anomalias Craniofaciais, ao Programa de Residência em Gerenciamento de Enfermagem em Clínica Médica e Cirúrgica e ao Programa de Residência de Vigilância em Saúde e Controle de Infecção, oferecidos pela Universidade Estadual do Oeste do Paraná (UNIOESTE).

A coleta de dados foi realizada nos meses de março de 2020 a março de 2021, junto ao serviço de triagem de pacientes da referida instituição de saúde, que consiste em um hospital geral, com atendimento exclusivo ao sistema único de saúde (SUS) e com capacidade para 210 leitos (BUGS TV, et al., 2021). O referido hospital conta com ambulatórios de especialidades, Centro Cirúrgico (CC), Centro Obstétrico (CO), Unidade de Terapia Intensiva (UTI) Adulto, UTI Pediátrica, UTI Neonatal, Unidade de Cuidado Intermediário (UCI), Alojamento Conjunto Pediátrico, Ala Clínica, Ala Ortopédica e Pronto Socorro (PS) (BUGS TV, et al., 2021).

Os residentes de enfermagem que cumpriam as escalas de trabalho de 06 horas diárias, e com o apoio de uma enfermeira e de uma técnica de enfermagem, eram responsáveis por determinar o fluxo dos atendimentos por meio da triagem de pacientes e acompanhantes. 
Inicialmente os enfermeiros residentes abordavam os pacientes com o objetivo de levantar informações voltadas para estabelecer o fluxo correto de atendimentos no setor. Para a atividade de triagem eram utilizados três instrumentos distintos, elaborados pelos profissionais responsáveis pelo serviço de triagem da instituição investigada, com base nos protocolos de manejo clínico do paciente COVID-19 estabelecidos pelo Ministério da Saúde (BRASIL, 2021). Um dos instrumentos era destinado para a condução da triagem de pacientes adultos, outro instrumento era destinado para triar acompanhantes e/ou visitantes e o outro instrumento era utilizado para triar pacientes pediátricos.

\section{DISCUSSÃO}

O serviço de triagem dos pacientes foi planejado e estruturado de acordo com as orientações sanitárias nacionais e internacionais vigentes, com o objetivo de evitar a disseminação da COVID-19 por meio da adoção de medidas preventivas (OSHA, 2021). O espaço físico destinado a essa atividade era localizado em uma área estratégica, com acesso ao pronto socorro, tomografia, enfermarias e UTI COVID, permitindo o correto fluxo de pacientes e acompanhantes para os diferentes setores da instituição investigada.

Para a realização da triagem dos pacientes, os profissionais de enfermagem deviam atender as normas de biossegurança quanto ao uso dos Equipamentos de Proteção Individual (EPI) para precaução respiratória (gotículas e aerossóis) fazendo uso de máscara N95, máscara facial, gorro, avental descartável não esterilizado e luvas de procedimento (JUNIOR JCFP, et al., 2020; USA, 2021). No entanto, no início da pandemia, devido a dificuldade de aquisição de EPIs, houveram relatos de inúmeras instituições de saúde que conseguiam fornecer todos os EPIs, contrapondo com as recomendações governamentais vigentes. Estudo recente revelou que $43,9 \%$ dos trabalhadores da saúde não tiveram acesso às máscaras do tipo N95 e 67,6\% não tiveram acesso aos protetores faciais, aumentando assim o risco de exposição dos profissionais da saúde (ANTUNES CMTB, et al., 2020).

Durante a coleta das informações prioritárias, norteadas pelos instrumentos de triagem elaborados pelo serviço, também eram coletados os dados vitais dos casos suspeitos por meio de termômetro digital, oxímetro de pulso, estetoscópio e esfigmomanômetro, vistos que, em conjunto com a anamnese, configuram uma boa abordagem para as atividades triagem.

De março a junho de 2020, todos os pacientes com sinais clínicos sugestivos para COVID-19 eram encaminhados para as "Unidades Covid" e tinham suas demandas de saúde atendidas nesses setores. A partir de julho de 2020, o referido hospital adotou a testagem rápida para COVID-19 em todos os pacientes sintomáticos que buscavam o serviço, otimizando o fluxo de pacientes de forma a diminuir a disseminação da doença.

O teste rápido molecular (ID NOW ${ }^{\mathrm{TM}}$ ) era solicitado pelo médico via prontuário eletrônico institucional e em seguida era comunicado o Serviço Intra Hospitalar de Coleta de Amostras Laboratoriais (SIHCAL) de forma a viabilizar a dispensação do material para que o enfermeiro pudesse realizar a testagem. Para a realização da técnica de coleta de material biológico era necessário adotar as seguintes medidas: higienizar as mãos; explicar ao paciente o procedimentos e orientar os possíveis desconfortos; entregar uma folha de papel descartável para higienizar as narinas após a coleta; solicitar ao paciente para sentar, abaixar a máscara e inclinar a cabeça para trás; inserir o swab de coleta com direção ao assoalho nasal até atingir a região da nasofaringe; realizar movimentos suaves de fricção e rotação por alguns segundos. Caso não fosse possível realizar a coleta via narina, a mesma deveria ser realizada via cavidade oral (PETRUZZI G, et al., 2020).

O resultado da análise do material coletado era disponibilizado em até 30 minutos após a testagem, e de acordo com o resultado, o paciente era direcionado à unidade de destino seguindo fluxo unidirecional, estabelecido protocolarmente. Importante destacar que quando a técnica de coleta de swab nasofaríngeo não é realizada de forma correta, há maior possibilidade de se obter resultados não conclusivos, aumentado o risco de contaminação e culminando na necessidade de novas coletas.

Durante o período experienciado, de acordo com o contexto epidemiológico local, foram instituídas várias normativas internas relacionadas à autorização/proibição de visitas e acompanhantes na tentativa de 
diminuir a disseminação da doença, sendo que no, final de 2020, foi autorizado a permanência de acompanhantes para pacientes menores de 18 anos, maiores de 60 anos, e com deficiência física/intelectual internados em leitos "não COVID". Para os pacientes com testagem positiva, as estratégias adotadas institucionalmente foram as "visitas on-line" viabilizadas por chamadas de vídeo via WhatsApp.

Em meio a crise mundial provocada por um vírus respiratório com alta proliferação e letalidade, acreditamos que a implementação do serviço de triagem tenha contribuído para aumentar a segurança dos trabalhadores da instituição em questão. As ações desenvolvidas na triagem dos pacientes e acompanhantes eram realizadas por meio de abordagem holística e humanizada, buscando acolhê-los e valorizando suas queixas principais. Embora a maior preocupação sanitária fosse a contenção da proliferação viral, quando o cuidado é voltado para seres humanos, tais aspectos não poderiam ser desvalorizados.

A inserção dos residentes de enfermagem no serviço de triagem atuando no enfrentamento da COVID19 contribuiu para a formação de profissionais comprometidos com a profissão, que de forma ética e responsável, atuaram no histórico cenário pandêmico, estabelecendo o fluxo adequado dos pacientes com suspeita ou com confirmação de infecção por SARS-CoV-2com a finalidade de evitar a disseminação da doença. Destacamos a necessidade de uma ampla discussão com os residentes que se encontramem treinamento em serviço com incentivo à reflexão sobre as práticas desenvolvidas, sobre as suas possibilidades e os seus limites, de forma a contribuir com o aprimoramentoprofissionale promover a transformaçãoindividual dos mesmos. Considerando o atual contexto sanitário e epidemiológico, o referido serviço de triagem continua em funcionamento, sem previsão de término das atividades.

\section{AGRADECIMENTOS}

Agradecemos a toda equipe da coordenação de enfermagem, da equipe de enfermagem da triagem, dos enfermeiros residentes que contribuíram para a excelência do cuidado prestado à referida clientela.

\section{REFERÊNCIAS}

1. ANTUNES CMTB, et al. Relato de experiência dos atendimentos de enfermagem em triagem para o diagnóstico da COVID-19 em profissionais da saúde. Nursing (São Paulo),2020; 23(269): 4773-4780.

2. BRANCO A, et al. Serviço de emergência hospitalar: fluxos de atendimento a pacientes suspeitos ou confirmados para covid-19. Enfermagem em Foco, 2020; 11(1): 199-204.

3. BRASIL. Ministério da Saúde. Secretaria de Vigilância em Saúde. Doença pelo Coronavírus COVID-19 Semana Epidemiológica 8 (21/2/2021 a 27/2/2021).2021. Disponível em: https://www.gov.br/saude/ptbr/media/pdf/2021/marco/05/boletim_epidemiologico_covid_52_final2.pdf. Acessado em 16 de abril de 2021

4. BRASIL D, et al. Tenda COVID-19: serviço de triagem especializado, uma análise temporal do perfil de pacientes atendidos. Rev. Bras. Enferm. 2021; 74(1).

5. BUGS TV, et al. Avaliação da acurácia dos diagnósticos de enfermagem em um hospital universitário. Enfermería Global, 2018; 17(4): 166-201.

6. CAETANO R, et al. Desafios e oportunidades para telessaúde em tempos da pandemia pela COVID-19: uma reflexão sobre os espaços e iniciativas no contexto brasileiro. Cadernos de Saúde Pública, 2020; 36.

7. DOREMALEN NV, et al. Aerosol and surface stability of SARS-CoV-2 as compared with SARS-CoV-1. New England journal of medicine, 2020; 382(16): 1564-1567.

8. ESTEVÃO A. COVID-19. Acta Radiológica Portuguesa, 2020; 32(1): 5-6.

9. GARCIA LP. Uso de máscara facial para limitar a transmissão da COVID-19. Epidemiologia e Serviços de Saúde, 2020; 29.

10. GUIMARÃES ASM, et al. Atuação da equipe multiprofissional em saúde, no cenário da pandemia por COVID19. Health Residencies Journal (HRJ), 2020; 1(2).

11. JUNIOR JCFP et al. A. Atuação de acadêmicos de enfermagem nas ações de enfrentamento da covid-19 em comunidades ribeirinhas do amazonas: relato de experiência. Revista Eletrônica Acervo Saúde, 2020:12, (10): 5049.

12. KAWAKAMI RMSA, et al. Experiências de Gestão e Educação de Enfermagem durante a triagem da COVID-19 em uma Clínica Integrada. Saúde Coletiva (Barueri), 2020; 10(59): 4494-4507.

13. LIMA CKT, et al. The emotional impact of Coronavirus 2019-nCoV (new Coronavirus disease). Psychiatry Res, 2020; 287(11): 2915. 
14. LOURENÇÃO LG. Engajamento no trabalho entre participantes de programas de residência e desenvolvimento profissional em enfermagem. Revista Brasileira de Enfermagem, 2018; 71(Suppl.4), 1487-1492.

15. MACHADO R, et al. Análise da gestão e atividade clínica do serviço de angiologia e cirurgia vascular do CHUP durante a pandemia covid-19, no período de 1 de março a 31 de maio de 2020, e lições aprendidas. Angiologia e Cirurgia Vascular / Publicação Oficial SPACV / www.acvjournal.com. 2020; 16(3): 115-119.

16. OCCUPATIONAL SAFETY AND HEALTH ADMINISTRATION (OSHA). Diretrizes para a Preparação dos Locais de Trabalho Para o COVID-19.

17. OLIVEIRA, WA. COVID-19: Desafios e oportunidades da enfermagem brasileira. Revista de Saúde-RSF,2020; 7(2).

18. PETRUZZI G, et al. COVID-19: Nasal and oropharyngeal swab. Head \& neck, 2020; 42(6): 1303-1304.

19. SILVA GF, et al. Atuação do residente de enfermagem no enfrentamento à covid-19 no município de Cascavel/PR: relato de experiência. Revista Varia Scientia - Ciências da Saúde, 2020; 6(2).

20. SILVEIRA JLO, et al. Monitoramento da qualidade da amostra para análise de RT-PCR da COVID-19 no LACEN-BA. Revista Baiana de Saúde Pública 2021; 45(1): 158-167.

21. TEMIME L, et al. A Conceptual Discussion About the Basic Reproduction Number of Severe Acute Respiratory Syndrome Coronavirus 2 in Healthcare Settings. Clinical Infectious Diseases, 2021; 72(1): 141-143.

22. UNITED STATES OF AMERICA (USA). Centers for Disease Control and Prevention. COVID-19 updates. Atlanta: Centers for Disease Control and Prevention; d2020.

23. VIEIRA LMF, et al. COVID-19 -Diagnóstico Laboratorial para Clínicos.Scientific Electronic Library Online. 2020. 